\title{
Nucleus Basalis Involvement in Conditioned Neuronal Responses in the Rat Frontal Cortex
}

\author{
Greg C. Rigdon and James H. Pirch \\ Department of Pharmacology, Texas Tech University Health Sciences Center, Lubbock, Texas 79430
}

\begin{abstract}
Rat frontal cortex neurons exhibit alterations in firing in response to a 2 sec tone cue followed by rewarding medial forebrain bundle (MFB) stimulation. Nucleus basalis neurons supply up to $75 \%$ of the cortical cholinergic innervation. The nucleus basalis and $\mathrm{ACh}$ have been implicated as playing a role in cognitive function. Three experiments were designed to test the hypothesis that the nucleus basalis cholinergic system is involved in the generation of conditioned neuronal responses in the rat frontal cortex. (1) Local microinjection of the cholinergic antagonist, atropine, into the frontal cortex suppressed the conditioned responses of 22 of 25 cortical single units. (2) Unilateral kainic acid lesioning of the nucleus basalis resulted in a significant decrease in the proportion of units exhibiting conditioned responses in the cortex ipsilateral to the lesion (25\%) compared to the proportion of responding units from the cortex of untreated animals $(70 \%)$. (3) When the firing rates of units encountered in the region of the nucleus basalis were monitored during presentation of the cue-MFB paradigm, 28 of 38 unit recordings exhibited significant increases or decreases in firing rate. Therefore, the results of the experiments indicate that the nucleus basalis cholinergic neurons are involved in the generation of conditioned neuronal responses in the rat frontal cortex.
\end{abstract}

Single neurons in the rat frontal cortex exhibit increases or decreases in firing rate in response to a cue that is immediately followed by some meaningful event (Pirch and Peterson, 1981; Pirch et al., 1983, 1985b; Rigdon and Pirch, 1985). The responses exhibit many of the characteristics of a conditioned response. (The unit responses studied in this report are referred to as "conditioned unit responses." Since the responses cannot be categorized as purely classical or operant conditioned responses, some would argue that a better term would be "conditioning-related" response or "analog of conditioning.") The conditioning paradigm used in the following study was a $2 \mathrm{sec}$ tone cue followed by rewarding medial forebrain bundle (MFB) stimulation. Single-unit responses have been generated using either food reward or MFB stimulation as the event in the paradigm (J. H. Pirch, unpublished observations). The advantages of using rewarding MFB stimulation as the meaningful event in this paradigm have been discussed previously (Pirch et al., 1981). The single-unit responses develop with training and extinguish if the MFB stimulation is discontinued. The cue and event must be paired for development of maximal responses (Pirch et al., 1983). When tested in a discrimination paradigm, $94 \%$ of the units that exhibited conditioned responses had sig-

Received Nov. 1, 1985; revised Mar. 3, 1986; accepted Mar. 5, 1986.

We would like to thank Dr. William $H$. Lyness for his excellent assistance and advice. This research was supported by the Tarbox Parkinson's Disease Institute and NIMH Grant MH29653.

Correspondence should be addressed to Greg C. Rigdon, U.S.E.P.A., Neurotoxicology Division, MD-74B, Research Triangle Park, NC 27711.

Copyright (c) 1986 Society for Neuroscience $0270-6474 / 86 / 092535-08 \$ 02.00 / 0$ nificantly larger responses to the reinforced cue than to the nonreinforced cue (Rucker et al., 1985). The unit responses exhibit the same characteristics (develop with training, extinction, etc.) whether recorded from awake or urethane-anesthetized rats (Pirch et al., 1985a). Our laboratory is interested in uncovering the brain regions and neurotransmitters involved in the generation of these conditioned responses. The experiments discussed in this report were designed to test the hypothesis that the nucleus basalis cholinergic system is involved in the generation of conditioned unit responses in the rat frontal cortex.

Pathological and pharmacological research indicates that the neurotransmitter ACh is involved in cognitive function. Choline acetyltransferase (ChAT) activity, acetylcholinesterase activity, and high-affinity choline uptake are all decreased in the cortex of victims of Alzheimer's disease (Bowen et al., 1982; Davies, 1979; Davies and Maloney, 1976; Perry et al., 1977; Reisine et al., 1978; Sims et al., 1980, 1983; White et al., 1977), a disorder characterized by profound loss of memory and cognitive function (Alzheimer, 1907). Neuronal cell counts in the nucleus basalis of Meynert of Alzheimer's disease victims are greatly decreased compared to age-matched controls (Nagai et al., 1983; Price et al., 1982; Whitehouse et al., 1981). The nucleus basalis of Meynert in primates and the nucleus basalis region in rats provide up to $75 \%$ of the cortical cholinergic innervation (Hartgraves et al., 1982; Johnston et al., 1979, 1981; Wenk et al., 1980). Administration of the anticholinergic drugs atropine and scopolamine results in deficits in memory and cognition in animals and humans (see Bartus et al., 1982; Spencer and Lal, 1983, for reviews).

Studies conducted in our laboratory have demonstrated that microinjection of procaine or GABA into the rat nucleus basalis region suppresses conditioned single-unit responses in the frontal cortex (Rigdon and Pirch, 1984). Both agents were used to inhibit the firing of neurons in the nucleus basalis. Three experiments were designed to investigate the involvement of the nucleus basalis cholinergic system in the generation of conditioned neuronal responses in the frontal cortex by determining: (1) the effects of local pharmacological blockade of cholinergic receptors on conditioned single-unit responses in the frontal cortex; (2) the effects of neurotoxin lesion of the nucleus basalis on the cortical conditioned responses; and (3) whether neurons in the nucleus basalis region exhibit conditioned responses to the same paradigm used to elicit conditioned responses in the frontal cortex. A preliminary report has appeared elsewhere (Rigdon et al., 1985).

\section{Materials and Methods}

\section{Implantation of electrodes and cannulae}

Adult male albino rats (Sprague-Dawley descent) were used in all experiments. Animals were implanted under pentobarbital ancsthesia (50 $\mathrm{mg} / \mathrm{kg}$, i.p.) after pretreatment with atropine $(7.5 \mathrm{mg} / \mathrm{kg}$, s.c.). A monopolar, stainless-steel stimulating electrode $(200 \mu \mathrm{m}$ diameter, $0.5 \mathrm{~mm}$ bare tip) was placed unilaterally into the medial forebrain bundle and 
2 ground screws were secured in the parietal bones. The guide cannulae for recording electrodes were placed over burr holes above the frontal cortex $2 \mathrm{~mm}$ anterior to bregma and $1.5 \mathrm{~mm}$ left and right of midline. Guide cannulae were not necessary when using the urethane-anesthetized preparation. For experiments requiring intracranial microinjection, an external cannula was constructed from a 23 gauge stainlesssteel needle. Dummy and internal cannulae for microinjection were made from 30 gauge short dental needles. The entire assembly was covered with dental acrylic. Two 0.5 inch, 4-40 machine screws were embedded in the acrylic to allow attachment to modified stereotaxic equipment to restrict movement of the animal's head.

\section{Training}

Animals prepared for awake recording were trained in a Plexiglas restraining box. Animals prepared for recording under urethane anesthesia were trained in a Skinner box. Optimum currents for self-stimulation of the MFB were determined by allowing an animal access to a lever that, when pressed, resulted in delivery of a $500 \mathrm{msec}$ train of electrical stimulation (100 Hz, $0.5 \mathrm{msec}$ monophasic square-wave pulse) to the MFB. The current supporting the highest rate of lever pressing was used for stimulation of the MFB during later training and experimentation. Animals were trained to associate a $2 \mathrm{sec}$ tone cue $(2900 \mathrm{~Hz})$ with rewarding MFB stimulation (at least 200 trials). Trials were presented at random intervals of 8-35 sec. Timing of intervals, tone presentation, and delivery of MFB stimulation were accomplished with a microcomputer.

\section{Unit recording}

Units were recorded from either awake, sedated (diazepam, $10 \mathrm{mg} / \mathrm{kg}$, s.c.), or anesthetized (urethane, $1.2-1.3 \mathrm{~g} / \mathrm{kg}$, i.p.) rats. To record from units in the awake state, an animal was placed in a restraint cage and its implant attached to modified stereotaxic equipment. A tungsten microelectrode (Fredrick Haer, $12 \mathrm{M} \Omega$ impedence, medium tip profile) was lowered into the cortex through the guide cannula until the first discernible spiking activity was encountered. In the urethane-anesthetized animals, the skull overlying the frontal cortex was exposed and holes drilled. Exposed wound edges were painted with $5 \%$ lidocaine cream to minimize the possibility of the animal experiencing any pain. The holes were filled with bone wax to prevent drying of the dura, and the animal was transferred to an electrophysiological chamber. A bolt in the animal's implant was fixed to stereotaxic equipment and a tungsten microelectrode lowered into the cortex via a hydraulic microdrive. The locus of first discernible spiking activity was recorded, and no neurons deeper than $1700 \mu \mathrm{m}$ below this locus were included in the studies to insure that all units were within the cortex. First activity is usually encountered at a depth of 300-500 $\mu \mathrm{m}$, and the cortex is approximately $2 \mathrm{~mm}$ thick.

Only cortical neurons that generated large positive-first deflection action potentials were used in experiments 1 and 2 . This type of action potential is presumably generated by pyramidal-shaped neurons (Humphrey, 1979) and can be kept isolated for long periods of timc. Action potentials were amplified with a Grass P15 AC microelectrode preamplifier $(300 \mathrm{~Hz}$ low-frequency and $3 \mathrm{kHz}$ high-frequency, half-amplitude cutoffs) and a secondary amplifier.

\section{Data analysis}

Analysis was carried out on-line. Action potentials were fed into an amplitude analyzer to discriminate them from background activity. The output pulses were fed into an event counter interfaccd with a microcomputer programmed to acquire peristimulus-time histograms. Sampling began $2 \mathrm{sec}$ before the onset of the tone and continued for a total of $4 \mathrm{sec}$. The sampling period for each trial was divided into $100 \mathrm{msec}$ time bins ( 20 prior to tone, 20 during tone) and terminated at the onset of MFB stimulation. Cumulative histograms were obtained for a minimum of 10 or a maximum of 50 trials. The $2 \mathrm{sec}$ response period was divided into two $1 \mathrm{sec}$ periods; one occurring just after tone onset and the other preceding MFB stimulation. To examine the response of individual units, comparisons were made between the number of counts per $100 \mathrm{msec}$ time bin prior to tone onset versus the 2 time periods after tone onset using a 2-way analysis of variance (ANOVA). A unit was considered to have exhibited a response if the firing rate during one or both of the time periods after tone onset differed significantly from the rate prior to tone onsct $(p<0.05)$.
Treatment effects were determined in the following manner: (1) If the neuron exhibited a response during one of the response time periods prior to treatment, but did not exhibit a response after treatment, an effect was considered to have occurred. (2) If the neuron exhibited a conditioned response both before and after treatment, then the number of counts per bin during the $2 \mathrm{sec}$ pretone period prior to treatment was compared to the analogous period posttreatment ( $t$ test). If the pretone firing rates were not significantly different $(p<0.05)$, then the response periods pre- and posttreatment were compared ( $t$ test) to determine if the magnitude of the response had been altered. If the pretone counts were altered after treatment and the unit still exhibited a conditioned response, then the treatment was considered to have had no effect.

\section{Drugs and chemicals}

The following drugs and chemical compounds were used: pentobarbital sodium (Sigma Chemical Co.), atropine sulfate (United States Biochemical Co.), lidocaine (Astra Pharmaceutical Products), urethane (Mallinckrodt), diazepam (Roche), '3-acetyl coenzyme A (New England Nuclear), and kainic acid (Sigma).

\section{Experiment 1: Microinjection of atropine into the frontal cortex}

Cannulae for frontal cortex microinjection were placed approximately $1 \mathrm{~mm}$ anterior to recording sites, with cannulae angled toward the recording electrode. This placed the tip of the injection cannulae in the cortical layers less than $0.5 \mathrm{~mm}$ anterior to the recording site. After obtaining a pretreatment conditioned response from a unit, $0.5 \mu \mathrm{l}$ of atropine solution $(8 \mu \mathrm{g} / \mu \mathrm{l}$ in $0.9 \%$ sterile saline) or saline vehicle was microinjected over a $1 \mathrm{~min}$ period. A second histogram was then obtained to ascertain the effect of the antagonist on the conditioned unit response. Both awake and urethane-anesthetized animals were used. The concentration of atropine was in the range of the concentrations used to obtain muscarinic blockade when iontophoretically applying atropine: $7-14 \mu \mathrm{g} / \mu \mathrm{l}$, or 10-20 mM (Bevan et al., 1975; Mclennan and Hicks, 1978). The shape of the unit's action potentials was monitored to insure that the effects seen were not the result of a local anesthetic effect of atropine.

\section{Experiment 2: Neurotoxin lesion of nucleus basalis}

Animals were anesthetized with pentobarbital. A 30 gauge needle was lowered into the nucleus basalis $-1.0 \mathrm{~mm}$ posterior to bregma, $2.6 \mathrm{~mm}$ lateral to bregma, $7.2 \mathrm{~mm}$ below dura (Wenk et al., 1984)-through a hole drilled in the skull and $0.5 \mu \mathrm{l}$ of sodium phosphate solution containing $0.5 \mu \mathrm{g}$ of kainic acid was injected over a $1 \mathrm{~min}$ period. The needle was left in place for $5 \mathrm{~min}$ after the injection was completed. The hole was filled with bone wax and the scalp sutured back in place. Animals were allowed a week to recover. After recovery, animals were prepared for recording of frontal cortex units in the urethane-anesthetized state.

Upon completion of a recording session, the animal was killed and bilateral punches of tissue from frontal cortex and hippocampus obtained. Subsequently, neurochemical analysis of ChAT activity was performed on the punches. Activity was determined by the method of Bull and Oderfeld-Nowak (1971). Proteins were determined by Lowry protein analysis (Lowry et al., 1951).

\section{Experiment 3: Conditioned unit responses in the nucleus basalis region}

Animals were prepared for awake recording with microelectrode guide cannulae placed over the nucleus basalis. Coordinates for the recording were $1.0 \mathrm{~mm}$ posterior to bregma, $2.6-3.0 \mathrm{~mm}$ lateral to midline, and 6.0-8.0 mm below dura. Some animals were also implanted with bilateral stainless-steel stimulating electrodes placed $1.5 \mathrm{~mm}$ deep in the frontal cortex site previously used for unit recording. This electrode was used in an attempt to antidromically identify units in the nucleus basalis region as projecting to the frontal cortex. Criteria for antidromic identification were (1) all-or-none action potential following cortical stimulation and (2) the ability to follow greater than $100 \mathrm{~Hz}$ stimulation. After the final recording session, the animal was killed and a $1 \mathrm{~mA}$ anodal current was passed through the electrode $(30 \mathrm{sec})$ to mark the region from which recordings were obtained. The brain was removed and a histological examination performed to determine if the recording electrode had becn in the nucleus basalis region. 
A



$\mathbf{B}$

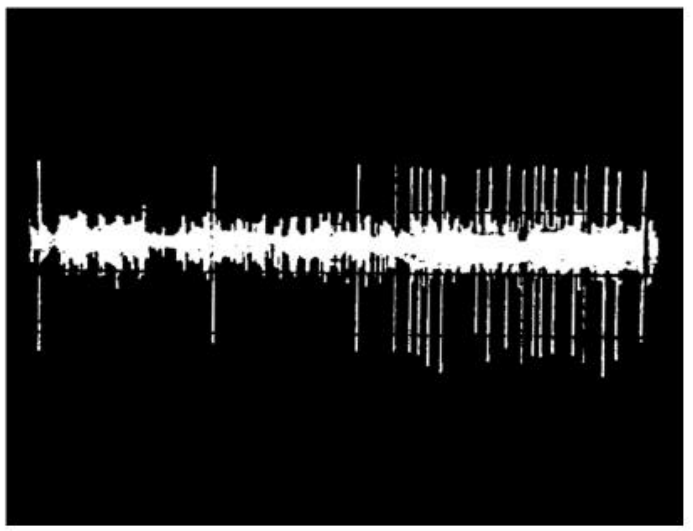

I TONE I

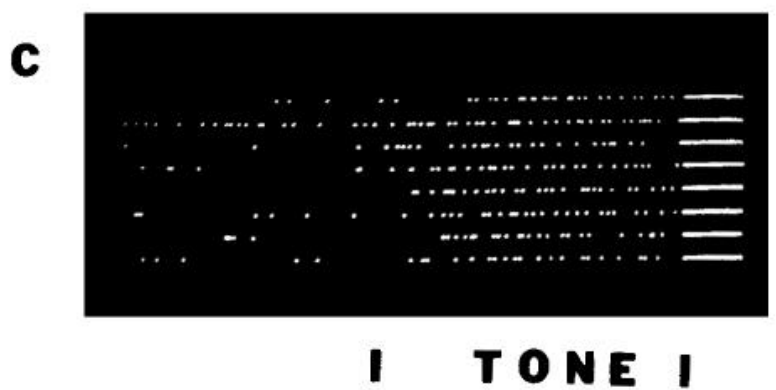

Figure 1. Single unit from rat frontal cortex that exhibited excitatory conditioned response. $A$, Positive-first deflection action potential (5 sweeps), $B$, Oscilloscope trace of neuronal response during 1 trial of cue-event paradigm. Sweep time, approximately $4 \mathrm{sec}$. $C$, Raster-stepper trace of conditioned neuronal response ( 8 trials).

\section{Results}

Unit recordings were obtained from awake and urethane-anesthetized animals in the following experiments. An example of a frontal cortex unit action potential and an excitatory response from an awake rat is given in Figure 1.
BEFDRE ATRDPINE


TONE
AFTER ATRDPINE
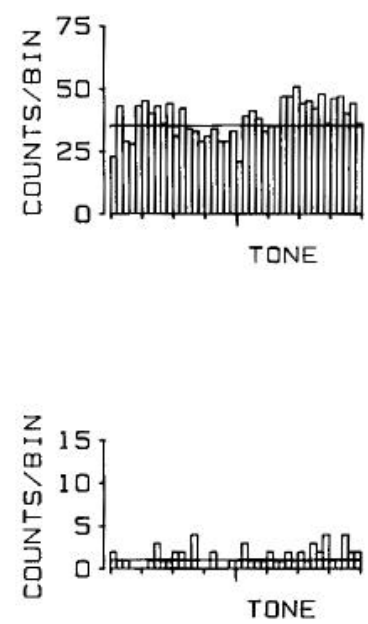

Figure 2. Histograms obtained from 2 units in frontal cortex with excitatory conditioned responses before atropine microinjection into the frontal cortex. Responses were significantly reduced after drug administration. Top pair of histograms from 10 trials; bottom pair, 20 trials.

\section{Experiment 1}

Atropine was microinjected into the frontal cortex to determine the effect of blockade of muscarinic receptors on cortical conditioned neuronal responses. Fifty-eight male rats were used in this study. After isolating an action potential with the desired characteristics (positive-first deflection, large amplitude) and obtaining a conditioned response to the tone cue, $4 \mu \mathrm{g}$ of atropine in $0.5 \mu \mathrm{l}$ of saline was microinjected $(0.5 \mu \mathrm{l} / \mathrm{min})$ within $0.5 \mathrm{~mm}$ (anterior) of the recording site. Units were then retested to determine the drug effect on the conditioned response. Saline microinjections were used as a control. Ten units were encountered that exhibited an increased firing rate in response to the cue and 15 units that exhibited a decreased firing rate during the cue. Atropine treatment significantly suppressed the conditioned response of 9 of the 10 excited (Fig. 2) and 13 of 15 inhibited units (Fig. 3). Saline microinjections $(0.5 \mu \mathrm{l})$ into the frontal cortex had no effect on the responses of the 5 units tested.

\section{Experiment 2}

Experiments were performed using urethane-anesthetized animals. Kainic acid $(0.5 \mu \mathrm{g})$ was used for unilateral lesioning of neuronal cell bodies in the nucleus basalis region of 4 rats. Because evidence indicates that unilateral nucleus basalis lesions cause small decreases in the amplitude of event-related slow potentials recorded from the cortex contralateral to the lesion (Pirch et al., 1986) and cause deficits in performance of tests of learning and memory (Lo Conte et al., 1982), conditioned neuronal responses from 4 untreated animals were used as controls. The results of the neurochemical analysis are presented in Figure 4. The ChAT activity in the frontal cortex ipsilateral to the lesion (mean, $3.88 \mu \mathrm{mol} / \mathrm{hr} / \mathrm{g}$ protein) was reduced significantly $(p<0.05$, paired $t$ test) compared to ChAT activity in frontal cortex contralateral to the lesion (mean, $8.28 \mu \mathrm{mol} /$ $\mathrm{hr} / \mathrm{g}$ protein). Hippocampal ChAT activity was not significantly reduced, indicating that the kainic acid did not spread out of the nucleus basalis region. Twenty-eight single-unit recordings were obtained from frontal cortex on the lesioned side and 17 from the nonlesioned side.

Seven units encountered during microelectrode drives through the cortex ipsilateral to the nucleus basalis lesion exhibited con- 

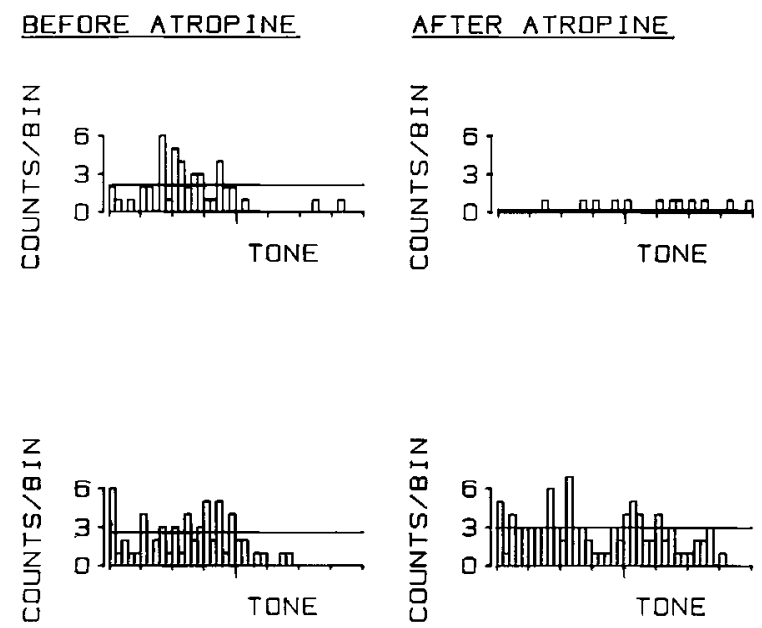

Figure 3. Histograms obtained from 2 units in frontal cortex with inhibitory conditioned responses before microinjection into the frontal cortex. Responses were significantly reduced after drug administration. Top pair of histograms from 40 trials; bottom pair, 25 trials.

ditioned responses to the tone cue; 4 were inhibited and 3 were excited. The firing rate of the remaining 21 units did not change significantly in response to the tone cue. The mean counts per bin during the pre- and postcue periods of all single units recorded from ChAT-depleted cortex are presented in Figure 5. Of the 17 units recorded from the frontal cortex contralateral to the nucleus basalis lesion, 9 had significant responses ( 3 inhibited, 6 excited), and 8 failed to respond (Fig. 6). Eleven of the 27 units recorded from the frontal cortex of the untreated animals had increased firing rates in response to the cue, 8 responded with a significant decrease in firing, and 8 failed to respond (Fig. 7). Therefore, $25 \%$ of the units from ChAT-depleted cortex exhibited conditioned responses, $52.9 \%$ of the units from the contralateral side of treated animals responded, and $70.4 \%$ of the units recorded from untreated animals responded to the tone cue.

Statistical analysis was performed using a $2 \times 2$ table and $\chi^{2}$ analysis. The proportion of single units exhibiting a conditioned response in the ChAT-depleted cortex was found to be significantly different from the proportion of responding units in the cortex of untreated animals. The proportion of units exhibiting conditioned responses in the cortex contralateral to the nucleus basalis lesions was not significantly different from that of responding units from the cortex of untreated animals. No significant differences were found for the pretone (spontaneous) firing rates of units from ChAT-depleted cortex (4.92 spikes/ sec), nonlesioned cortex of treated animals (5.94 spikes/sec), and cortex of untreated animals (4.08 spikes/sec).

\section{Experiment 3}

Ten rats were implanted for recording of single units from the nucleus basalis region. Awake, diazepam-sedated rats were used in this study. The same coordinates used for lesioning of the nucleus basalis were used for unit recording. The action potentials recorded from units in the nucleus basalis were often small and difficult to isolate, and the action potentials from more than one unit were therefore analyzed together in some of the recordings. Cumulative histograms were obtained from 38 unit recordings from the nucleus basalis region. Units encountered in the nucleus basalis region exhibited robust excitatory (Fig. 8) and inhibitory conditioned responses. Of the 38 unit recordings, $28(73.7 \%)$ exhibited significant increases or decreases in firing rate in response to the cue. The responses extinguished if the



Figure 4. Choline acetyltransferase (ChAT) activity (in $\mu \mathrm{mol} \mathrm{ACh} / \mathrm{hr} /$ $\mathrm{g}$ protein) from 4 animals with unilateral kainic acid lesions of the nucleus basalis. First set of bars represents mean ChAT activity in frontal cortex punches; second set of bars, mean ChAT activity in hippocampal samples. Open bars represent samples from side of brain contralateral to lesions; striped bars, samples from sidc of brain ipsilateral to nucleus basalis lesions. Asterisk indicates significant difference between sides $(p<0.05$, unpaired $t$ test).

MFB stimulation did not follow the tone cue in the 5 units tested for extinction. Nineteen units responded by excitation (Fig. 9), 8 by inhibition, and 1 with a biphasic response (Fig. 10). Only 1 of 12 units tested was antidromically activated by frontal cortex stimulation. It exhibited an excitatory response. Subsequent histological examination verified that unit recordings in each of the animals were obtained from the region in which nucleus basalis neurons are located (ventral globus pallidus-substantia innominata).

\section{Discussion}

The results from these experiments demonstrate that (1) conditioned neuronal responses in the rat frontal cortex are suppressed by local antagonism of cholinergic muscarinic receptors, (2) the proportion of cortical neurons exhibiting responses is significantly decreased after kainic acid lesioning of the nucleus basalis cholinergic input to the frontal cortex, and (3) neurons in the nucleus basalis region exhibit responses to the same conditioning paradigm used to elicit cortical neuronal responses. Previously we demonstrated that microinjection of the inhibitory compounds, procaine or GABA, into the nucleus basalis reversibly suppresses conditioned cortical neuronal responses (Rigdon and Pirch, 1985). The rat nucleus basalis is comprised of a group of large, ChAT-positive neurons interspersed with neurons of the substantia innominata and ventral globus pallidus (Armstrong et al., 1983; Fibiger, 1982; Mesulam, 1983; Saper, 1984; Wainer et al., 1984; Wenk et al., 1980). Because the neurons are not located in a homologous region, it is not possible to destroy basalis neurons selectively and study the effects on cortical unit responses. The experiments discussed in this report were designed to provide 3 different means of testing the hypothesis that the nucleus basalis neurons are involved in the generation of conditioned cortical unit responses. While no single experiment could prove that the nucleus basalis neurons are involved in the cortical unit responses, the evidence as a whole builds a strong case in support of the hypothesis.

Cholincrgic antagonists have long been associated with loss of memory and decreased ability to learn in animals and humans (Bartus et al., 1982; Spencer and Lal, 1983). Experiment $1 \mathrm{dem}-$ onstrated that local microinjection of atropine suppresses the magnitude of cortical conditioned neuronal responses.

Electrolytic or neurotoxin lcsions of thc rat nucleus basalis cause decreases in the activity of enzymes necessary for the production and inactivation of $\mathrm{ACh}$ in the frontal cortex (Flicker et al., 1983; Hartgraves et al., 1982; Johnston et al., 1979, 1981; Lehmann et al., 1980; Wenk et al., 1984). The same types of lesion have also been demonstrated to cause deficits in the performance of behavioral tasks involving learning and memory 

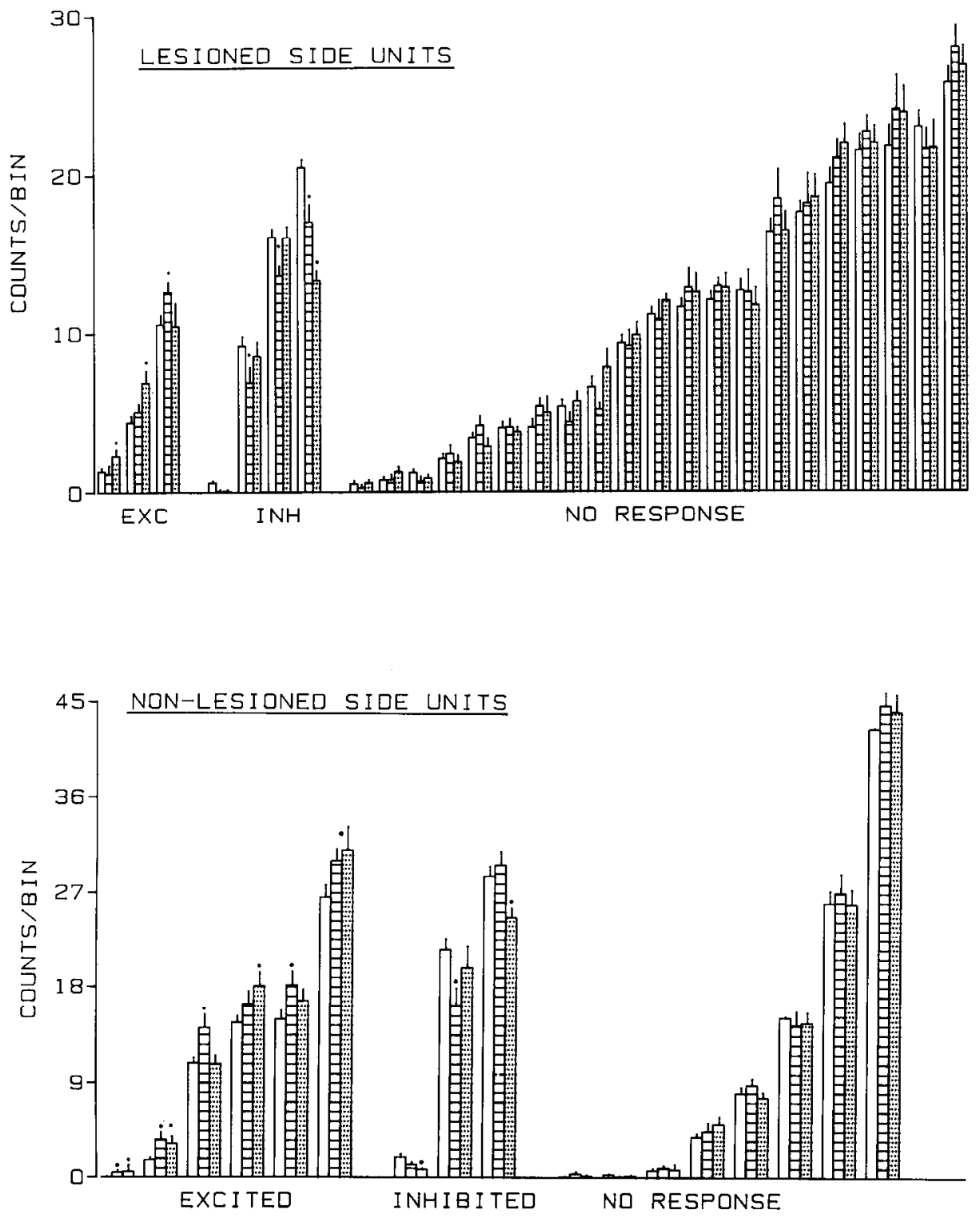

Figure 6. All units from cortex contralateral to nucleus basalis lesion in treated animals. Mean counts per bin during $2 \mathrm{sec}$ pretone period (open bars), during 1 st second after tone onset (striped bars), and during 2nd second after tone onset (dotted bars). Dots atop error bars indicate significant difference $(p<0.05)$ from pretone period.

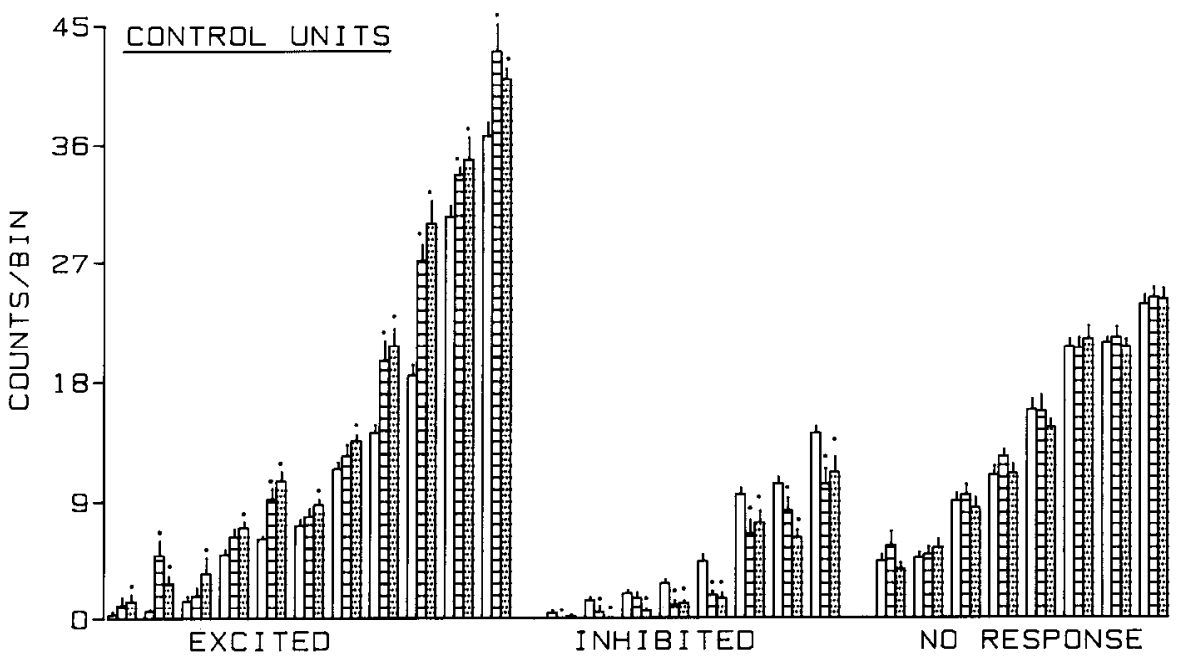

Figure 7. All units from frontal cortex of untreated animals. Mean counts per bin during 2 sec pretone period (open bars), during 1 st second after tone onset (striped bars), and during 2nd second after tone onset (dotted bars). Dots atop error bars indicate significant difference $(p<0.05)$ from pretone period. 

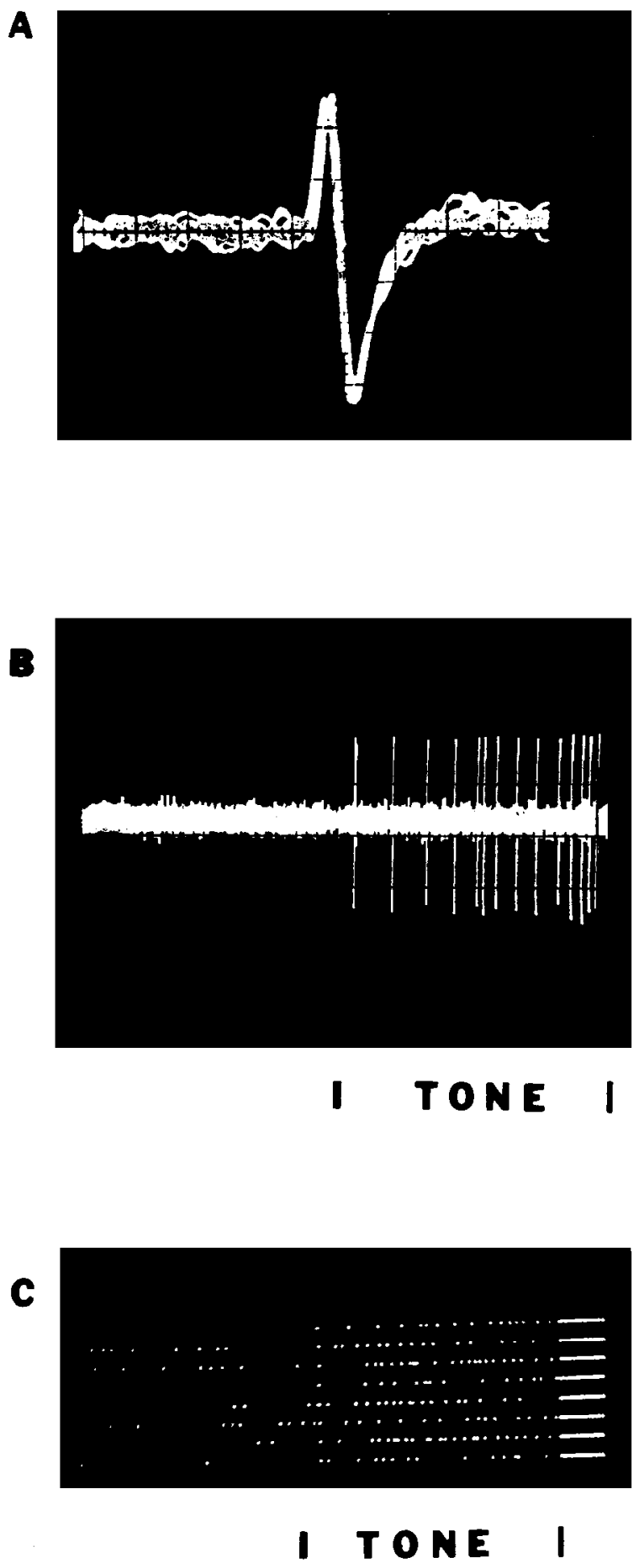

Figure 8. Single unit from the nucleus basalis region that exhibited an excitatory conditioned response. $A$, Action potential waveform $(10$ sweeps). $B$, Oscilloscope trace of neuronal response during 1 trial of cue-event paradigm. Sweep time, 4 sec. $C$, Raster-stepper trace of neuronal response to tone cue ( 8 trials). Sweep time, just over 4 sec. Vertical lines indicate onset of tone and MFB stimulation.

(Flicker et al., 1983; Friedman et al., 1983; Lo Conte et al., 1982). Lesions of the nucleus basalis also reduce the proportion of neurons in the frontal cortex that exhibit conditioned responses (experiment 2).

If nucleus basalis neurons are involved in the generation of cortical responses, then logic dictates that the basalis neurons should exhibit responses to the same paradigm. Experiment 3 demonstrated that neurons within the region in which basalis neurons are located exhibit conditioned responses.

Alzheimer's disease is characterized by a loss of cholinergic neurons in the nucleus basalis of Meynert and decreased activity of ChAT and AchE in the frontal cortex and hippocampus (see Coyle et al., 1983; Terry and Davies, 1980; Terry and Katzman, 1983, for reviews). Victims of Alzheimer's disease exhibit decreases in the amplitude of the contingent negative variation, a conditioned slow negative wave recorded from the scalp in response to a cue followed by some meaningful event (Rizzo et al., 1984). Similar event-related slow potentials may be recorded from the rat frontal cortex using the same conditioning paradigm that elicits conditioned unit responses (Pirch et al., 1983, 1985a). The amplitudes of these slow potentials are decreased by (1) local blockade of cholinergic receptors, (2) electrolytic or neurotoxin lesioning of the nucleus basalis, and (3) microinjection of inhibitory compounds into the nucleus basalis (Pirch et al., 1984, 1986).

Other investigators have demonstrated that neurons in the frontal cortex (Aou et al., 1983a, b; Fuster et al., 1982) and nucleus basalis region (DeLong, 1971; Rolls, 1982; Wilson et al., 1984) exhibit conditioning-related responses. The results reported here, along with previous studies from our laboratory, provide direct support for an electrophysiological link between the neurochemical and behavioral studies discussed above.

Both inhibitory and excitatory cortical unit responses were suppressed by local microinjection of atropine, and the proportion of both types of response decreased after lesioning the nucleus basalis. One possible explanation is that both excitatory and inhibitory cortical unit responses are the direct result of cholinergic input from the nucleus basalis. Both inhibitory and excitatory unit responses were recorded from the nucleus basalis rcgion. Howcver, only 1 unit from the nucleus basalis region was antidromically identified in experiment 3 (excitatory response). This is not surprising in light of the findings of AstonJones and coworkers (1984) that less than $8 \%$ of the units encountered in the nucleus can be antidromically identified following frontal cortex stimulation. Bccausc the basalis neurons are interspersed with other types of neurons throughout the ventral globus pallidus-substantia innominata region, the experiment only demonstrated that neurons in the region of the nucleus basalis exhibit both types of conditioned responses. Whether the units were actually cholinergic basalis neurons is unknown.

Electrophysiological evidence indicates that $\mathrm{ACh}$ acts as an excitatory neuromodulator in the frontal cortex, possibly through a second messenger substance, cGMP (Swartz and Woody, 1979, 1984; Woody et al., 1978). If this is the case, then neuronal input from the nucleus basalis may act to enhance the effects of other excitatory neurotransmitters (e.g., glutamate) on neurons in the frontal cortex. Thus, the excitatory responses observed would be the result of enhancement of excitatory input to the neuron being recorded, and inhibitory responses would be caused by excitation of inhibitory interneurons impinging on the recorded cells.

Antagonism of muscarinic receptors often altered the spontaneous firing rate of cortical units (see Fig. 3). This would suggest a tonic cholinergic input. The spontaneous firing rates of 13 of the 24 units in experiment 1 were significantly altered after atropine microinjection (6 increased, 7 decreased). Both increases and decreases occurred in units exhibiting excitatory and inhibitory responses. Lesion of the nucleus basalis caused no alteration in the spontaneous firing rate of cortical neurons but did significantly reduce the number of responding units. Thus, while this antagonism of tonic cholinergic input may occasionally explain the suppression of conditioned unit response, it seems unlikely in the majority of the cases. 




Figure 9. Units from nucleus basalis region that exhibited excitatory response to tone-MFB paradigm. Open bars represent mean counts per bin during 2 sec pretone period; striped bars, mean counts per bin during 1 st second after tone onset; dotted bars, mean counts per bin during 2 nd second after tone onset. Vertical lines, SE. Asterisk indicates significant difference $(p<0.05)$ from pretone period.

The results from these experiments point to a role for the nucleus basalis cholinergic system in the generation of conditioned unit responses in the frontal cortex. Uncovering the generators of conditioned unit responses may provide insights into the physiology of learning and memory. Further investigations need to be conducted to determine if the development of conditioned unit responses in the nucleus basalis is a necessary prerequisite for conditioned responses to occur in the frontal cortex.

\section{References}

Alzheimer, A. (1907) Uber eine eigenartige Erkrandung der Hirnrinde. Allg. Z. Psychiatr. Psychisch-gerichtlich Med. 64: 146-148.

Aou, S., Y. Oomura, and H. Nishino (1983a) Influence of acetylcholine on neuronal activity in monkey orbitofrontal cortex during bar press feeding task. Brain Res. 275: 178-182.

Aou, S., Y. Oomura, H. Nishino, A. Inokuchi, and Y. Mizuno (1983b) Influence of catecholamines on reward-related neuronal activity in monkey orbitofrontal cortex. Brain Res. 267: 165-170.

Armstrong, D. M., C. B. Saper, A. I. Levey, B. H. Wainer, and R. D. Terry (1983) Distribution of cholinergic neurons in rat brain: Demonstrated by the immunocytochemical localization of choline acetyltransferase. J. Comp. Neurol. 216: 53-68.

Aston-Jones, G., R. Shaver, and T. Kinan (1984) Cortically projecting

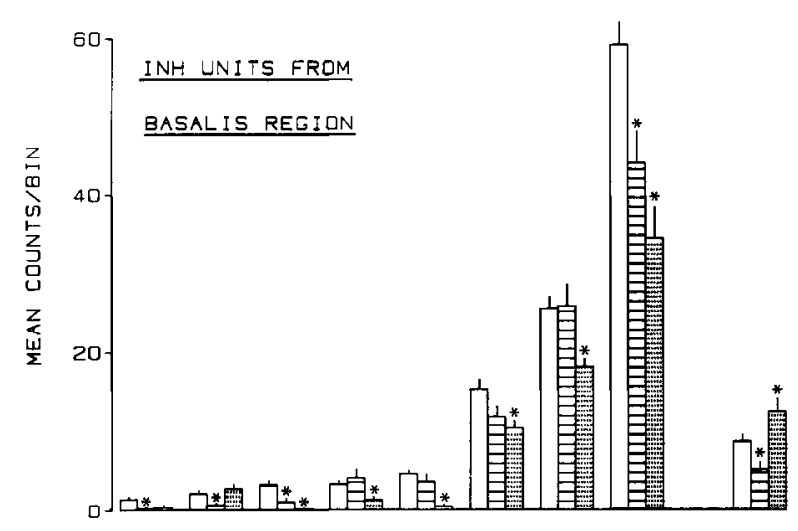

Figure 10. Units from nucleus basalis region with inhibitory or biphasic responses to tone-MFB paradigm. Open bars represent mean counts per bin during $2 \mathrm{sec}$ pretone period; striped bars, mean counts per bin during 1 st second after tone onset; dotted bars, mean counts per bin during 2 nd second after tone onset. Vertical lines, SE. Asterisk indicates significant difference $(p<0.05)$ from pretone period. nucleus basalis neurons in the rat are physiologically heterogenous. Neurosci. Lett. 46: 19-24.

Bartus, R. T., R. L. Dean, B. Beer, and A. S. Lippa (1982) The cholinergic hypotheses of geriatric memory dysfunction. Science 217: 408-417.

Bevan, P., C. M. Bradshaw, and E. Szabadi (1975) The antagonism of neuronal responses to acetylcholine by atropine: A quantitative study. Brain Res. 88: 568-571.

Bowen, D. M., J. S. Benton, J. A. Spillane, C. C. T. Smith, and S. J. Allen (1982) Choline acetyltransferase activity and histopathology of frontal neocortex from biopsies of demented patients. J. Neurol. Sci. 57: 191-202.

Bull, $G_{\text {. }}$, and B. Oderfeld-Nowak (1971) Standardization of a radiochemical assay of choline acetyltransferase and a study of the activation of the enzyme in rabbit brain. J. Neurochem. 18: 935-941.

Coyle, J. T., D. L. Price, and M. R. DeLong (1983) Alzheimer's disease: A disorder of cortical cholinergic innervation. Science 219: 1184 1190.

Davies, P. (1979) Neurotransmitter-related enzymes in senile dementia of the Alzheimer type. Brain Res. 171: 319-327.

Davies, P., and A. J. F. Maloney (1976) Selective loss of central cholinergic neurons in Alzheimer's disease. Lancet 1: 1403.

DeLong, M. R. (1971) Activity of pallidal neurons during movement. J. Neurophysiol. 34: 414-427.

Fibiger, H. C. (1982) The organization and some projections of cholinergic neurons of the mammalian forebrain. Brain Res. Rev. 4:327388.

Flicker, C., R. L. Dean, F. L. Watkins, S. K. Fisher, and R. T. Bartus (1983) Behavioral and neurochemical effects following neurotoxic lesions of a major cholinergic input to the cerebral cortex in the rat. Pharmacol. Biochem. Behav. 18: 973-981.

Freidman, E., B. Lerer, and J. Kuster (1983) Loss of cholinergic neurons in the rat neocortex produces deficits in passive avoidance learning. Pharmacol. Biochem. Behav. 19: 309-312.

Fuster, J. M., R. J. Bauer, and J. P. Jervey (1982) Cellular discharge in the dorsolateral prefrontal cortex of the monkey in cognitive tasks. Exp. Neurol. 77: 679-694.

Hartgraves, S. L., P. L. Mensah, and P. H. Kelly (1982) Regional decreases of cortical choline acetyltransferase after lesions of the septal area and in the area of nucleus basalis magnocellularis. Neuroscience 7: 2369-2376.

Humphrey, D. R. (1979) Extracellular single unit recording method. In Electrophysiological Techniques, pp. 199-259, Society for Neuroscience, Washington, DC.

Johnston, M. V., M. McKinney, and J. T. Coyle (1979) Evidence for a cholinergic projection to neocortex from neurons in the basal forebrain. Proc. Natl. Acad. Sci. USA 76: 5392-5396.

Johnston, M. V., M. McKinney, and J. T. Coyle (1981) Neocortical cholinergic innervation: A description of extrinsic and intrinsic components in the rat. Exp. Brain Res. 43: 159-172.

Lehmann, J., J. I. Nagy, S. Atmadja, and H. C. Fibiger (1980) The 
nucleus basalis magnocellularis: The origin of a cholinergic projection to the neocortex of the rat. Neuroscience 5: 1161-1174.

Lo Conte, G., L. Bartolini, F. Casamenti, I. Marconi-Pepeu, and G. Pepeu (1982) Lesions of cholinergic forebrain nuclei: Changes in avoidance behavior and scopolamine actions. Pharmacol. Biochem. Behav. 17: 933-937.

Lowry, O. H., N. J. Rosenbrough, A. L. Farr, and R. S. Randall (1951) Protein measurement with the Folin phenol method. J. Biol. Chem. 193: 265-275.

Mclennan, H., and T. P. Hicks (1978) Pharmacological characterization of the excitatory cholinergic receptors of rat central neurones. Neuropharmacology 17: 329-334.

Mesulam, M.-M., E. J. Mufson, B. H. Wainer, and A. I. Levey (1983) Central cholinergic pathways in the rat: An overview based on an alternative nomenclature (Ch1-Ch6). Neuroscience 10: 1185-1201.

Nagai, J. T., P. L. McGeer, J. H. Peng, E. G. McGeer, and C. E. Dolman (1983) Choline acetyltransferase immunohistochemistry in brains of Alzheimer's disease patients and controls. Neurosci. Lett. 36: 195199.

Perry, E. K., R. H. Perry, G. Blessed, and B. E. Tomlinson (1977) Necropsy evidence of central cholinergic deficits in senile dementia. Lancet $1: 189$.

Pirch, J. H., and S. L. Peterson (1981) Event-related slow potentials and activity of single neurons in rat frontal cortex. Int. J. Neurosci. 15: $141-146$.

Pirch, J. H., M. J. Corbus, and T. C. Napier (1981) Auditory cue preceding intracranial stimulation induces event-related potential in rat frontal cortex: alterations by amphetamine. Brain Res. Bull. 7 : 399-404.

Pirch, J. H., M. J. Corbus, and G. C. Rigdon (1983) Single-unit and slow potential responses from rat frontal cortex during associative conditioning. Exp. Neurol. 82: 118-130.

Pirch, J. H., W. H. Lyness, M. J. Corbus, and G. C. Rigdon (1984) Pharmacological and other approaches for investigation of neurochemical substrates of event-related slow potentials. In Substrates of Event-Related Slow Potentials. Seventh International Conference on Event-Related Slow Potentials of the Brain, Florence, Italy.

Pirch, J. H., M. J. Corbus, and I. Ebcnczor (1985a) Conditioned cortical slow potential responses in urethane anesthetized rats. Int. J. Neurosci. 25: 207-218.

Pirch, J. H., M. J. Corbus, and G. C. Rigdon (1985b) Conditioningrelated single unit activity in the frontal cortex of urethane anesthetized rats. Intern. J. Neurosci. 25: 263-271.

Pirch, J. H., M. J. Corbus, G. C. Rigdon, and W. H. Lyness (1986) Generation of cortical event-related slow potentials in the rat involves nucleus basalis cholinergic innervation. EEG Clin. Neurophysiol. 63 . 464-475.

Price, J. L., P. J. Whitehouse, R. G. Struble, A. W. Clark, J. T. Coyle, M. R. DeLong, and J. C. Hedreen (1982) Basal forebrain cholinergic systems in Alzheimer's disease and related dementias. Neurosci. Commen. 2: 84-92.

Rcisine, T. D., H. Yamamura, E. D. Bird, E. Spokes, and S. J. Enna (1978) Pre- and post-synaptic neurochemical alterations in Alzheimer's disease. Brain Res. 159: 477-482.

Rigdon, G. C., and J. H. Pirch (1984) Microinjection of procaine or GABA into the nucleus basalis magnocellularis affects cue-elicited unit responses in the rat frontal cortex. Exp. Neurol. 85: 283-296.

Rigdon, G. C., and J. H. Pirch (1985) Nucleus basalis involvement in conditioned neuronal responses in the rat frontal cortex. Soc. Neurosci. Abstr. 11: 1108 .

Rizzo, P. A., G. Albani, C. Cicardi, M. Spadaro, and C. Morocutti (1984) Effects of distraction on the contingent negative variation in presenile dementia and normal subjects. Neuropsychobiology 12:112114.

Rolls, E. T. (1982) Neuronal mechanisms underlying the formation and disconnection of associations between visual stimuli and reinforcement in primates. In Conditioning: Representation of Involved Neural Functions, C. D. Woody, ed., pp. 363-373, Plenum, New York.

Rucker, H. K., M. J. Corbus, and J. H. Pirch (1985) Single unit correlates of conditioning-related tone discrimination in the frontal cortex of urethane anesthetized rats. Soc. Neurosci. Abstr. 11: 1108.

Saper, C. B. (1984) Organization of cerebral cortical afferent systems in the rat. II. Magnocellular basal nucleus. J. Comp. Neurol. 222: 313-342.

Sims, N. R., D. M. Bowen, S. I. Allen, C. C. T. Smith, D. Neary, D. J. Thomas, and A. N. Davison (1983) Presynaptic cholinergic dysfunction in patients with dementia. J. Neurochem. 40: 503-509.

Sims, N. R., D. M. Bowen, C. C. T. Smith, R. H. Flack, A. N. Davison, J. S. Snowden, and D. Neary (1980) Glucose metabolism and acetylcholine syntheses in relation to neuronal activity in Alzheimer's disease. Lancet $1:$ 333-336.

Spencer, D. G., and H. Lal (1983) Effects of anticholinergic drugs on learning and memory. Drug Dev. Res. 3: 489-502.

Swartz, B. E., and C. D. Woody (1979) Correlated effects of acetylcholine and cyclic guanosine monophosphate on membrane properties of mammalian neocortical neurons. J. Neurobiol. 10:465-488.

Swartz, B. E., and C. D. Woody (1984) Effects of intracellular antibodies to CGMP on responses of cortical neurons to extracellular application of muscarinic agonists. Exp. Neurol. 6: 388-404.

Terry, R. D., and P. Davies (1980) Senile dementia of the Alzheimer type. Annu. Rev. Neurosci. 3: 77-95.

Terry, R. D., and R. Katzman (1983) Senile dementia of the Alzheimer type. Ann. Neurol. 14: 497-506.

Wainer, B. H., A. I. Levey, E. J. Mufson, and M.-M. Mesulam (1984) Cholinergic systems in mammalian brain identified with antibodies against choline acetyltransferase. Neurochem. Int. 6: 163-182.

Wenk, G. L., V. Bigl, and U. Meyer (1980) Cholinergic projections from magnocellular nuclei of the basal forebrain to cortical areas in rats. Brain Res. Rev, 2: 295-316.

Wenk, G. L., B. Cribbs, and L. McCall (1984) Nucleus basalis magnocellularis: Optimal coordinates for selective reduction of choline acetyltransferase in frontal neocortex by ibotenic acid injections. Exp. Brain Res. 56: 335-340.

White, P., C. R. Hiley, M. J. Goodhardt, L. H. Carrasco, J. P. Keet, I. E. I. Williams, and D. M. Bowen (1977) Neocortical cholinergic neurons in elderly people. Lancet $1: 668-670$.

Whitehouse, P. J., S. L. Price, A. W. Clark, J. T. Coyle, and M. R. DeLong (1981) Alzheimer disease: Evidence for selective loss of cholinergic neurons in the nucleus basalis. Ann. Neurol. 10:122-126.

Wilson, F. A. W., E. T. Rolls, S. Yaxley, S. J. Thorpe, G. V. Williams, and S. J. Simpson (1984) Responses of neurons in the basal forebrain in the behaving monkey. Soc. Neurosci. Abstr. 10: 128.

Woody, C. D., B. E. Swartz, and E. Gruen (1978) Effects of acetylcholine and cyclic GMP on input resistance of cortical neurons in awake cats. Brain Res. 158: 373-395. 